\title{
ACEi/ARB naif hastalarda sakubitril/valsartan başlanabilir mi?
}

\author{
Dr. Ahmet Çelik
}

Mersin Üniversitesi Tıp Fakültesi, Kardiyoloji Anabilim Dalı, Mersin

Sakubitril/Valsartan'ın (S/V) ilk faz III çalışması olan PARADIGM HF'de ACEi/ARB naif hasta olmadığından, çalışmaya alınan tüm hastalar ya önceden ACEi/ARB kullanmakta idi ya da randomizasyondan önce, ACEi başlandıktan bir süre sonra ACEi'i tolere edebilen hastalarda ACEi kesilip yerine S/V başlanmıştı. Dolayısıyla S/V'nin kılavuzlara girmesi de bu çalışmanın paralelinde olmuştur. ESC $2016 \mathrm{KY}$ kılavuzunda bir ACEi (veya ARB), beta-bloker ve MRA'yı optimal dozda alıp tolere eden ve ACC/AHA 2017 KY kılavuzunda ise MRA şartı aranmaksızın bir ACEi (veya ARB) ve beta-blokeri optimal dozda alıp tolere eden ancak buna rağmen semptomatik olan ambulatuar düşük ejeksiyon fraksiyonlu kalp yetersizliği (DEF-KY) hastalarında, KY nedeni ile hastaneye yatışları ve ölüm riskini azaltmak için hastaların kullandığg1 ACEi'yi S/V'ye değiştirme önerilmiştir. ${ }^{[1,2]}$

Bununla birlikte S/V'nin ACEi/ARB naif kronik DEF-KY'li hastalarda direkt başlanması konusu tartışılmaya başlanmıştı; fakat o güne ait veriler ışığında bunu önermek kolay değildi. TRANSITION ve PIONEER-HF, yeni başlangıçlı DEF-KY ve ACEi/ ARB-naif DEF-KY hastalarında veri sağlayan ilk randomize çalışmalardır.

TRANSITION VE PIONEER HF çalışmaları DEF-KY hastalarında; akut KY epizodu ardından klinik stabilizasyon sonrası, S/V başlanmasını değerlendiren çalışmalardır. TRANSITION çalışması DEF-KY hastalarında akut KY epizodu sonrasında, klinik stabilizasyon sonrası $\mathrm{S} / \mathrm{V}$ 'nin güvenlik ve tolerabilitesini değerlendirmeyi amaçlayan bir çalışmadır. Hastalara $\mathrm{S} / \mathrm{V}$ hastane içinde veya taburculuktan hemen sonra erken dönemde başlanmıştır. ${ }^{[3]} 10$. haftada hastaların $\% 86$ 's1 ara verilmeksizin 2 hafta veya daha uzun süredir S/V tedavisi alabilmiş ve çalışmaya alınan hastaların yaklaşık yarısı hedef doz olan 2x200 mg/gün S/V primer sonlanım noktasına 10. haftada ulaşmıştır. Yan etkiler ve yan etkilere bağlı $\mathrm{S} / \mathrm{V}$ kesilmesi hastane içi ve ayaktan takip edilen hastalarda benzerdir. ${ }^{[4]}$ TRAN-
SITION çalışmasında S/V'nin tolerabilitesi gerçek yaşamda beta-blokerler ve ACEi/ARB tolerabilitesi ile kıyaslanabilir düzeyde saptanmıştır. ${ }^{[4,5]}$

PIONEER-HF çalışması akut dekompanse KY ile hastaneye yatırılmış olan stabil, DEF-KY'li hastalarda $\mathrm{S} / \mathrm{V}$ 'nin hastanede başlanmasının güvenliği, tolerabilitesi ve etkinliğini enalapril ile karşılaştırarak değerlendirmek için tasarlanmıştır. ${ }^{[6]}$ Çalışmanın birinci sonlanım noktası, NT-proBNP' de 4. ve 8. haftalarda başlangıca göre olan zaman ortalamalı orantısal değişimdir. ${ }^{[6,7]}$ Çalışmada enalapril ile \%25' lik bir azalmaya kıyasla $\mathrm{S} / \mathrm{V}$ ile tedavi edilen hastalarda zaman ortalamalı NT-proBNP'de başlangıca göre \%47 azalma izlenmiştir. Bu istatistiksel olarak S/V'nin \%29 oranında daha fazla NT-proBNP azalma sağlaması anlamına gelmektedir (\%95 CI: 0.63-0.81; p<0.0001). [7] S/V kullanan grupta tedaviye başladıktan 1 hafta gibi kısa bir süre sonra NT-proBNP'de anlamlı düşüşler gözlenmiştir. Çalışmada güvenlik profili PARADIGM-HF çalışması ile benzer ${ }^{[2,4]}$ ve $\% 0,5$ 'ten fazla bir sıklıkta meydana gelen ciddi advers olayların oranları S/V ve enalapril grupları arasında benzer bulunmuştur. Bileşik ölümün son noktası, KY nedeni ile rehospitalizasyon, sol ventrikül asist device implantasyonu ve kalp nakli için listeye alınma S/V grubunda 41 hastada (\%9.3) enalapril grubunda 74 (\%16.8) görülmüştür (HR 0.54 \%95 CI 0.37-0.79; p=0.001). Fayda S/V grubunda ölüm ve rehospitalizasyonda azalma ile elde edilmiştir. Böyle bir klinik olayı 8 hafta haftalık takipte önlemek için tedavi edilmesi gere-

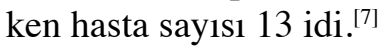

S/V'nin ACEi/ARB naif hastalarda başlanmas1 ile ilgili bu çalışmaların verilerine baktığımızda; PIONEER HF'deki hastaların yaklaşık \%34'ü ve TRANSITION çalışmasındaki hastaların ise \%29'u daha önce KY öyküsü olmayan yeni teşhis edilmiş hastalardı. PIONEER HF'deki hastaların \%50'si ve TRANSITION çalışmasındaki hastaların \%24'ü başvuru sırasında ACEi/ARB tedavisi almamakta idi. ${ }^{[4,7]}$ 
Tablo 1. ACEi/ARB naif hastaların dahil edildiği sakubitril/valsartan ile yapılan çalışmalar

\begin{tabular}{lcccc}
\hline & $\begin{array}{c}\text { Transition } \\
(\mathrm{S} / \mathrm{N})\end{array}$ & $\begin{array}{c}\text { Pioneer HF } \\
(\mathrm{S} / \mathrm{V} \text { vs ACEI })\end{array}$ & $\begin{array}{c}\text { Evaluate HF } \\
(\text { SN vs ACEI })\end{array}$ & $\begin{array}{c}\text { Prove HF } \\
(\mathrm{S} / \mathrm{V})\end{array}$ \\
\hline ACEi/ARB naif hasta sayısı & $241(\% 24)$ & $232(\% 52)^{*}$ & $44(\% 19)^{*}$ & $\begin{array}{c}48(\% 6) \text { hiç kullanmamış } \\
144(\% 18) \text { kullanıp bırakmış }\end{array}$ \\
Total hasta sayısı & & & $464(\% 100)$ & $794(\% 100)$ \\
\hline
\end{tabular}

*: Sakubitril/valsartan kolunda.

PIONEER-HF'den yakın zamanda sunulan veriler ACEi/ARB naif hastalarda S/V'nin, yatıs sonrasında sistolik kan basıncı baz alınarak doz titre edildiğinde hastaneye yatış sırasındaki birincil ve güvenlik uç noktaları üzerinde aynı faydalı etkisi olduğu gösterilmiştir. TITRATION çalışmasının post hoc analizinde hastaların $>\% 80$ 'inde sistolik kan basıncı $\geq 100 \mathrm{mmHg}$ üzerinde idi ve $\mathrm{S} / \mathrm{V}$ hedef dozuna yavaş yavaş titre edilmiştir. ${ }^{[8]}$ TRANSITION çalışmasında ise ACEi/ARB naif hastalarda $\mathrm{S} / \mathrm{V}$ başlanması, titre edilmesi ve hedef dozda idame edilmesi ACEi/ARB tedavisi alan hastalarla benzer saptanmıştır. ${ }^{[4]}$

PROVE HF çalışmasında DEF-KY'li hastalarda S/V başlanmasından sonraki NT-proBNP seviyelerindeki değişimin kardiyak yapısal ve fonksiyonel değişim ile olan ilişkisi incelenmiş ve 12 aylık takip sonucunda NT-proBNP deki azalma oranının sol ventrikül $\mathrm{EF}$, sistol ve diyastol sonu volümler, mitral E/e' oranı ve sol atriyal volüm indeksinde anlamlı düzelmeler sağladığı ve NT proBNP'deki azalmanın bu kardiyak yapısal ve fonksiyonel öğelerdeki düzelmeyle ilişkili olduğu gösterilmiştir. Çalışmaya alınan olguların 44'ü (\%6) hiç ACEi/ARB kullanmamış ve 144'ü (\%18) daha önceleri ACEi/ARB kullanmış ancak bırakmış olgulard1. Yeni tan $\mathrm{KY}$ olan ve/veya ACEi/ARB naif hastalardaki veriler ve sonuçlarda tüm çalışma sonuçlarıyla benzer çıkmıştır. Dolayısıyla S/V başlanan hastalarda görülen olumlu etkilerin ACEi/ARB naif hastalarda da benzer görülmesi S/V'nin kronik DEFKY hastalarında önceden ACEi/ARB tedavisi almayan hastalarda da kullanılabileceği anlamına gelen sevindirici bir gelişmedir. ${ }^{[9]}$

EVALUATE HF çalışmasında DEF-KY'li hastalarda S/V ile enalaprilin aortik stifnes üzerindeki etkileri kıyaslanmıştır. Primer sonlanım noktası 12. haftada santral aortik stifnesin bir ölçümü olan aort karakteristik impedans (Zc)'nin bazale göre değişimi idi. Sekonder sonlanım noktası ise 12. haftada NT proBNP, EF, global longitudinal strain, mitral anüler relaksasyon velositesi, mitral E/e' oran1, sol ventrikül diyastol ve sistol sonu hacim indeksleri, sol atriyum volüm indeksi ve ventriküler-vasküler çiftleşme oranlarının bazale göre değişimi idi. Çalışmaya toplam 464 hasta alınmıştır. S/V kolundaki olguların 44 tanesi (\%19) ACEi/ARB naif hastalar idi. Çalışma sonunda S/V'nin enalaprile kıyasla aortik stifnesi anlamlı olarak azaltmadığı saptanmıştır. ${ }^{[10]}$

S/V ile yapılan yakın zamanlı çalışmalarda ACEi/ ARB naif hastalarda alınmıştır. Tablo 1 bu çalışmalarda alınan hastaların sayıları ve ACEi/ARB naif hasta oranlarını göstermektedir.

Sonuç olarak; TRANSITION, PIONEER HF, EVALUATE HF ve PROVE HF çalışmaları, ACEi/ ARB naif hasta altgruplarında $S / V$ 'nin güvenliğini ve etkinliğini ortaya koyan kanıtlar sunması açısından önem arz etmektedir. Bu çalışmalardan gelen veriler 1şı̆̆ında ACEi/ARB naif DEF-KY hastalarında S/V'nin güvenle başlanabileceği söylenebilir.

\section{Kaynaklar}

1. Yancy CW, Jessup M, Bozkurt B, Butler J, Casey DE Jr, Colvin MM, et al. 2017 ACC/AHA/HFSA Focused Update of the 2013 ACCF/ AHA Guideline for the Management of Heart Failure: A Report of the American College of Cardiology/American Heart Association Task Force on Clinical Practice Guidelines and the Heart Failure Society of America. J Am Coll Cardiol 2017;70:776-803.

2. Ponikowski P, Voors AA, Anker SD, Bueno H, Cleland JGF, Coats AJS, et al. 2016 ESC Guidelines for the diagnosis and treatment of acute and chronic heart failure: The Task Force for the diagnosis and treatment of acute and chronic heart failure of the European Society of Cardiology (ESC)Developed with the special contribution of the Heart Failure Association (HFA) of the ESC. Eur Heart J 2016;37:2129-200.

3. Pascual-Figal D, Wachter R, Senni M, Belohlavek J, Noè A, Carr $\mathrm{D}$, et al. Rationale and design of TRANSITION: a randomized trial of pre-discharge vs. post-discharge initiation of sacubitril/valsartan. ESC Heart Fail 2018;5:327-36.

4. Wachter R, Senni M, Belohlavek J, Straburzynska-Migaj E, Witte $\mathrm{KK}$, Kobalava Z, et al. Initiation of sacubitril/valsartan in haemodynamically stabilised heart failure patients in hospital or early after discharge: primary results of the randomised TRANSITION study. Eur J Heart Fail 2019;21:998-1007.

5. Maggioni AP, Anker SD, Dahlström U, Filippatos G, Ponikowski P, Zannad F, et al. Are hospitalized or ambulatory patients with heart failure treated in accordance with European Society of Cardiology guidelines? Evidence from 12,440 patients of the ESC Heart Failure Long-Term Registry. Eur J Heart Fail 2013;15:1173-84. 
6. Velazquez EJ, Morrow DA, DeVore AD, Ambrosy AP, Duffy CI, McCague $\mathrm{K}$, et al. Rationale and design of the comParIson Of sacubitril/valsartaN versus Enalapril on Effect on nt-pRo-bnp in patients stabilized from an acute Heart Failure episode (PIONEER-HF) trial. Am Heart J 2018;198:145-51.

7. Velazquez EJ, Morrow DA, DeVore AD, Duffy CI, Ambrosy AP, McCague K, et al. Angiotensin-Neprilysin Inhibition in Acute Decompensated Heart Failure. N Engl J Med 2019;380:539-48.

8. Senni M, McMurray JJV, Wachter R, McIntyre HF, Anand IS, Duino $\mathrm{V}$, et al. Impact of systolic blood pressure on the safety and tolerability of initiating and up-titrating sacubitril/valsartan in patients with heart failure and reduced ejection fraction: insights from the TITRATION study. Eur J Heart Fail 2018;20:491-500.

9. Januzzi JL Jr, Prescott MF, Butler J, Felker GM, Maisel AS, McCague $\mathrm{K}$, et al. Association of Change in N-Terminal Pro-B-Type Natriuretic Peptide Following Initiation of Sacubitril-Valsartan Treatment With Cardiac Structure and Function in Patients With Heart Failure With Reduced Ejection Fraction. JAMA 2019;322:1-11.

10. Desai AS, Solomon SD, Shah AM, Claggett BL, Fang JC, Izzo J, et al. Effect of Sacubitril-Valsartan vs Enalapril on Aortic Stiffness in Patients With Heart Failure and Reduced Ejection Fraction: A Randomized Clinical Trial. JAMA 2019;322:1-10. 